\title{
The Efficacy and Prevalence of Montelukast Therapy in Cough-Variant Asthma Patients in Al-Kindy Teaching Hospital
}

\author{
Saba Jasim Hamdan* \\ Department of Pharmacology, Al-Kindy College of Medicine, University of Baghdad, Baghdad, Iraq
}

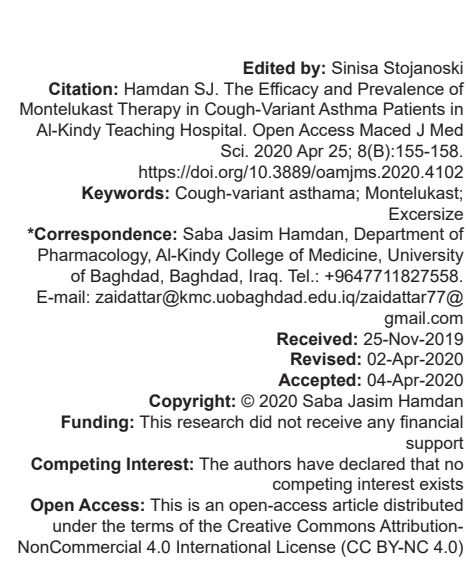

Introduction

Cough-variant asthma (CVA) is a type of asthma that is marked by a dry, non-productive chronic cough that lasts from 6 to 8 weeks. Mostly, it is nocturnal cough. In some cases, patients develop daytime cough as bad as nighttime cough, but have no other traditional asthma symptoms such as wheezing or shortness of breath. It does not include some of the other defining symptoms of asthma, such as chest tightness, wheezing when exhaling, shortness of breath, fluid in the lungs, productive cough, and trouble sleeping due to any of the above symptoms. Anyone can get CVA at any time, but it is common in young kids with childhood asthma [1]. People with CVA asthma often notice that coughing increases with exercise. Coughing may increase when they are exposed to asthma triggers or allergy causing substances such as dust or strong fragrances or when they are in cold air. Coughing of CVA may be due to bronchoconstriction, but the detailed causal relationship involved in cough and bronchoconstriction remains unknown. If left untreated, CVA can progress into more severe, chronic asthma. A recent study noted that " $30-40 \%$ of adult patients with CVA, unless adequately treated, may progress to classic asthma."
Another study indicated that CVA is one of the most common causes of coughing worldwide [2].

\section{Pathophysiology}

During a CVA and asthma episode, the airways narrow and produce excess mucus, making it difficult to breathe. In essence, all types of asthma are the result of an immune response in the bronchial airways. The airways of asthma patients are "hypersensitive" to certain triggers, also known as stimuli. It is usually classified as type I hypersensitivity. In type I hypersensitivity, B-lymphocytes are stimulated by CD4+ $\mathrm{TH} 2$ to produce $\lg \mathrm{E}$ antibodies specific to an antigen. Inhalation of antigens stimulates induction of TH2-type cells and releases interleukins IL-4 and IL-5. This leads to synthesis of $\operatorname{lgE}$ that binds to mucosal mast cells. Exposure of IgE-coated mast cells to the same antigen causes cross-linking of $\mathrm{IgE}$ and the release of chemical mediators [3]. In response to exposure to these triggers, the bronchi contract into spasm. Inflammation soon follows, leading to a further narrowing of the airways and excessive mucus production, which leads to coughing [4]. Bronchospasm may resolve spontaneously in $1-2 \mathrm{~h}$, or in about $50 \%$ of 
subjects, may become part of a "late" response, where this initial insult is followed 3-12 $\mathrm{h}$ later with further bronchoconstriction and inflammation [4].

Montelukast (Singulair ${ }^{\mathrm{TM}}$ ) is a cysteinyl leukotriene receptor antagonist, used for the maintenance treatment of asthma and to relieve symptoms of seasonal allergies and exercise-induced bronchospasm [5]. It acts by blocking the action of leukotriene D4 (and secondary ligands and leukotrienes C4 and E4) on the cysteinyl leukotriene receptor 1 (Cys-LTR1) in the lungs and bronchial tubes by binding to it [6].

\section{Objective}

This study was performed to evaluate the therapeutic effect of Montelukast in CVA and to measure the prevalence of Montelukast in usage CVA patients.

\section{Methods}

A cross-sectional study was conducted at Al-Kindy Teaching Hospital between the periods of January 2018 and April 2018. The patients were diagnosed by the Internal Medicine Consultant Clinic to have CVA. Patients were excluded if they have pregnancy, diabetes mellitus, heart failure, and drugs that may induce cough, for example, captopril. A convenient method of sampling was used in this study. Thirty patients with chronic cough (without wheezing and shortness of breath) for at least 8 weeks were recruited in the study. Then, Montelukast was administered for 4 weeks as $10 \mathrm{mg}$ oral dose tablet, once daily. The study protocol was approved by our institutional review board and conformed to the principles of the Declaration of Helsinki. After obtaining formal written consent from each patient, an interview using questionnaire was held to collect the data that were specifically prepared to meet the objectives of study including (age, sex, associated disease, and exacerbation factors). The data were prepared as frequencies and relative frequencies.

\section{Results}

Thirty patients participated in the study. Table 1 shows the number and percentage of patients in each demographic characteristic such as gender, occupation, and marital status. Males and females were nearly equal in number, jobless patients were more than employed patients, and married and unmarried patients are much nearly equal.
Table 1: Number of patients in different demographic characteristics

\begin{tabular}{lll}
\hline Demographic parameters & Frequency & Relative frequency (\%) \\
\hline Gender & 13 & \\
$\quad$ Male & 17 & 43.3 \\
$\quad$ Female & & 56.7 \\
Occupation & 11 & 36.7 \\
$\quad$ Employed & 19 & 63.3 \\
$\quad$ Jobless & & \\
Marital status & 16 & 53.3 \\
$\quad$ Married & 14 & 46.7 \\
$\quad$ Unmarried & & 16.7 \\
Address & 5 & 83.3 \\
$\quad$ Rural & 25 & \\
$\quad$ Urban & & \\
\hline
\end{tabular}

Table 2 shows the number and percentage of patients in each age group. The group which contained the largest number of patients was 41-59 years. The groups which contained the least number of patients were $17-25$ and $26-40$ years.

Table 2: Number of patients in different age groups (years)

\begin{tabular}{lll}
\hline Age groups (years) & Frequency & Relative frequency $(\%)$ \\
\hline $6-16$ & 9 & 30.0 \\
$17-25$ & 4 & 13.3 \\
$26-40$ & 4 & 13.3 \\
$41-59$ & 10 & 33.3 \\
$60-70$ & 3 & 10.0 \\
Total & 30 & 100.0 \\
\hline
\end{tabular}

Figure 1 shows the number and percentage of patients who have certain exacerbation factors. Dust was the most prevalent exacerbation factor in this study, while other factors (perfumes) were the least prevalent factor.

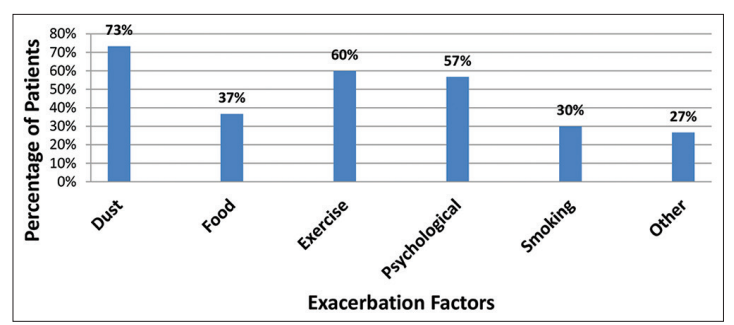

Figure 1: Prevalence of exacerbation factors among patients

Table 3 shows the number of patients who use Montelukast in different age groups were 6-16, 17-25, 26-40, 41-59, and 60-70 years.

Table 3: Montelukast use in different age groups (years)

\begin{tabular}{llll}
\hline Age groups (years) & \multicolumn{2}{l}{ Montelukast use } & Total \\
\cline { 2 - 3 } & Yes & No & \\
\hline $6-16$ & 9 & 0 & 9 \\
$17-25$ & 3 & 1 & 4 \\
$26-40$ & 2 & 2 & 4 \\
$41-59$ & 8 & 2 & 10 \\
$60-70$ & 0 & 3 & 3 \\
Total & 22 & 8 & 30 \\
\hline
\end{tabular}

Figure 2 shows the number and percentage of patients who used Montelukast and benefited from it. Vomiting patients showed the most benefit and syncope patients showed the least.

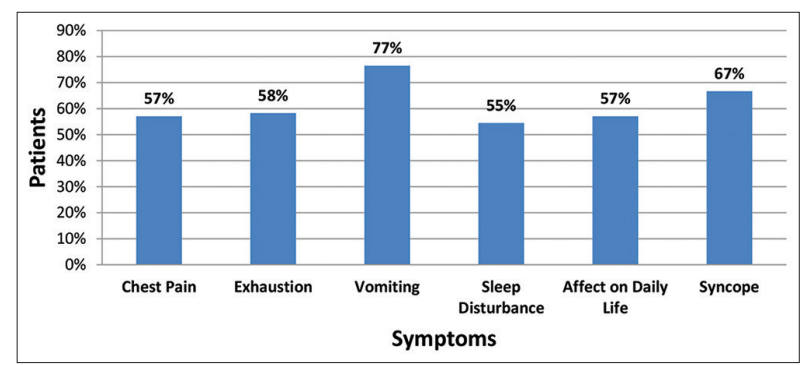

Figure 2: Patients benefited from Montelukast 


\section{Discussion}

Most of this study patients were living in urban areas, urban areas are known to have more industrialization and pollution, and this agrees with a study done by Hirshon et al. (2006), in which Maryland showed the highest rates of emergency department visits for chronic cough in urban areas [7]. A study performed by Sole et al. (2007) showed that the international prevalence of chronic cough-related symptoms was higher among those adolescents living in the urban centers in comparison to the rural ones in Brazil [8].

Dust was an exacerbation factor that more than two-thirds of patients in this study were complaining from, this agrees with a study by Tricia (1977), in which it suggests that dust exposure can have long-lasting effects on respiratory symptoms in chronic dry cough. More than half of this study patients had exercise to be a triggering exacerbation factor. An article was published by Khajotia et al. (2008) claims that $90 \%$ of asthmatic individuals and $35-45 \%$ of patients with allergic rhinitis are afflicted by exercise-induced asthma, while $3-10 \%$ of the general population is also believed to suffer from this condition. In this study, 18 patients were suffering from this condition and based on Leff et al. (1998) stated that Montelukast usage as a therapy offers significantly greater protection against exerciseinduced bronchoconstriction. Just after 12 weeks of Montelukast administration, patients have shown better control of their state without the need of B-agonist during or after exercise challenge [9]. Smoking was an exacerbation factor in a number of the study patients. A review conducted by Stapleton et al. (2011), has shown patients who smoke, and has poorer control than asthmatic nonsmokers. Airway mucosal permeability is increased in smokers, which could lead to an increased clearance of inhaled corticosteroids from the airways so in conclusion, cigarette smoking and passive smoking in asthmatics lead to detrimental effects in patient outcomes and effectiveness of steroid therapy [10]. In our study, other exacerbation factors were found to be the psychological condition of patients, in which a patient may develop a persistent cough in the absence of physical factors associated with respiratory system, but it occurs alongside with anxiety and stress. In a study that was published in 2018 by Wright MFA1, Balfour-Lynn IM1, found that $18 \%$ of the chronic cough patient included in their study were actually suffering from behavioral/psychiatric cough [11].

In Figure 2, chest pain was experienced by most patients in this study. After the administration of Montelukast, more than half showed an improving result due to the medication. A clinical trial was utilized by Al-Hamdani (2010) to evaluate the outcome of using Montelukast showed that patients who used Montelukast had their asthma symptom, chest wheezing, and pulmonary function test (PFT) values significantly improved at the end of the study compared to the first visit. All symptoms were significantly lower and PFT values were higher in the $2^{\text {nd }}$ group compared to the $1^{\text {st }}$ group. In conclusion, Montelukast sodium showed significant changes in asthma symptoms and PFT after 1 month of treatment [12]. Sleep disturbance or sleep apnea is a symptom that three-fourths of our patients suffered from, and about half of them improved after Montelukast. The Canadian Agency Drugs and Technologies in Health (2014) says that, according to one randomized clinical trial, oral Montelukast appears to be effective at improving respiratory disturbances in children with mild to moderate obstructive sleep apnea as determined by improvements in apnea-hypopnea index and obstructive apnea index scores [13]. Few of the patients in this study suffered from syncope as a symptom, Beckman (2002) states that cough syncope occurs primarily in middle-aged male smokers with chronic obstructive pulmonary disease. It has also been described in children with asthma [14]. Ojo and Ozoh (2016) had a case of cough syncope with temporary loss of consciousness that lasted for $3 \mathrm{~s}$. The patient showed significant improvement after being treated with a short course of oral steroids and salbutamol as needed and continued on inhaled steroids and Montelukast [15]. A study done by French et al. about impact of chronic cough on quality of life claimed that chronic cough was significantly associated with meaningful adverse psychosocial and physical effects on quality of life. Compared with individuals with no health-related dysfunction, it revealed that cough was associated with dysfunction in patients usual daily activities, particularly in the categories of ambulation, social interaction, sleep and rest, work, home management, and recreation [16]. According to a study done by Mincheva et al., in 2014, found that patients with chronic cough due to upper airway cough syndrome or gastroesophageal reflux disease but not asthma reported significant relief of their symptoms after 2 weeks of treatment with Montelukast [17].

\section{Conclusion}

The use of Montelukast leads to reduction in the frequency of chronic cough and the symptoms associated with it.

\section{Acknowledgment}

We would like to acknowledge the role of Dr. Zaid Al-Attar in writing and publishing this study. The study was funded from private sources by the author. 


\section{References}

1. Corrao WM. Pearls and pitfalls in the diagnosis of cough variant asthma. Allergy Asthma Proc. 2018;39(6):466-7. https://doi. org/10.2500/aap.2018.39.4168

PMid:30401324

2. Niimi A. Cough and asthma. Curr Respir Med Rev. 2011;7(1):47-54. PMid:22081767

3. Galli SJ, Tsai M. IgE and mast cells in allergic disease. Nat Med. 2012;18(5):693-704. https://doi.org/10.1038/nm.2755 PMid:22561833

4. Mason R, Broaddus VC, Martin T, King T, Schraufnagel D, Murray J, et al. Murray and Nadel's Textbook of Respiratory Medicine. Philadelphia, PA: Saunders; 2010. https://doi. org/10.1016/b978-1-4160-4710-0.00101-2

5. Hamdan SJ, Al-Attar Z, Hashim I. Prevalence of montelukast use as an add-on therapy among Iraqi asthmatics on treatment attending Al-Kindy teaching hospital and Al-Zahraa center of asthma and allergy. Open Access Maced J Med Sci. 2019;7(14):2246-50. https://doi.org/10.3889/oamjms.2019.645 PMid:31592270

6. Zubairi $A B$, Salahuddin $N$, Khawaja $A$, Awan $S$, Shah $A A$, Haque AS, et al. A randomized, double-blind, placebo-controlled trial of oral montelukast in acute asthma exacerbation. BMC Pulm Med. 2013;13:20. https://doi.org/10.1186/1471-2466-13-20 PMid:23537391

7. Hirshon JM, Weiss SR, LoCasale R, Levine E, Blaisdell CJ. Looking beyond urban/rural differences: Emergency department utilization by asthmatic children. J Asthma. 2006;43(4):301-6. https://doi.org/10.1080/02770900600623255 PMid:16809244

8. Sole D, Cassol VE, Silva AR, Teche SP, Rizzato TM, Bandim LC, et al. Prevalence of symptoms of asthma, rhinitis, and atopic eczema among adolescents living in urban and rural areas in different regions of Brazil. Allergol Immunopathol (Madr). 2007;35(6):248-53. https://doi.org/10.1157/13112991

PMid: 18047816
9. Leff JA, Busse WW, Pearlman D, Bronsky EA, Kemp J, Hendeles L, et al. Montelukast, a leukotriene-receptor antagonist, for the treatment of mild asthma and exercise-induced bronchoconstriction. New Engl J Med. 1998;339(3):147-52. https://doi.org/10.1056/nejm199807163390302 PMid:9664090

10. Stapleton M, Howard-Thompson A, George C, Hoover RM, Self TH. Smoking and asthma. J Am Board Fam Med. 2011;24(3):313-22. PMid:21551404

11. Wright MF, Balfour-Lynn IM. Habit-tic cough: Presentation and outcome with simple reassurance. Pediatr Pulmonol. 2018;53(4):512-6. https://doi.org/10.1002/ppul.23948 PMid:29363880

12. Al-Hamdani FY. Comparative clinical evaluation of ketotifen and montelukast sodium in asthmatic Iraqi patients. Saudi Pharm J. 2010;18(4):245-9. https://doi.org/10.1016/j.jsps.2010.07.001 PMid:23960734

13. Canadian Agency for Drugs and Technologies in Health. Montelukast for Sleep Apnea: A Review of the Clinical Effectiveness, Cost Effectiveness, and Guidelines. Ottawa: Canadian Agency for Drugs and Technologies in Health; 2014.

14. Beckman TJ. Syncope in an adult with uncontrolled asthma. South Med J. 2002;95(3):369-70. PMid: 11902710

15. Ojo OT, Ozoh O. Cough Syncope, an Unusual Presentation of Asthma in Adults. B45. Obstructive Lung Disease: Interesting Cases. American Thoracic Society International Conference Abstracts. New York: American Thoracic Society; 2016. p. A3587.

16. French CL, Irwin RS, Curley FJ, Krikorian CJ. Impact of chronic cough on quality of life. Arch Intern Med. 1998;158(15):1657-61. https://doi.org/10.1001/archinte.158.15.1657 PMid:9701100

17. Mincheva RK, Kralimarkova TZ, Rasheva M, Dimitrov Z, Nedeva D, Staevska M, et al. A real-life observational pilot study to evaluate the effects of two-week treatment with montelukast in patients with chronic cough. Cough. 2014;10(1):2. https://doi. org/10.1186/1745-9974-10-2

PMid:24649919 